\title{
Optimization of AA5083 Friction Stir Welding Parameters Using Taguchi Method
}

\author{
Abuajila RAWENI, Vidosav MAJSTOROVIĆ, Aleksandar SEDMAK, Srdjan TADIĆ, Snežana KIRIN
}

\begin{abstract}
In this study, Taguchi design was applied to find out the optimized set of friction steel welding parameters in terms of total crack energy, crack initiation energy, and crack propagation energy in weldments. Taguchi approach was used to design a set of welding experiments concerning rotational welding speed, traversing speed, and tool tilt angle. Welding variables were analyzed by means of Taguchi orthogonal arrays and signal-to-noise ratio analysis to find the optimum welding parameters. ANOVA analysis was used to determine the influence between each of these parameters.
\end{abstract}

Keywords: ANOVA analysis; crack initiation energy; crack propagation energy; friction stir welding; Taguchi method

\section{INTRODUCTION}

In the modern industry sector, quality and cost of products are an essential target. In the field of welding, friction stir welding (FSW) has become a technology of widespread interest because of its numerous advantages. On the other side, Taguchi robust design approach is a powerful statistical technique to make high quality product with no additional cost. In this study, friction stir welding is used to weld aluminum-magnesium alloy, AA5083, with Taguchi method applied to optimize input parameters (rotational speed, traversing speed and tool tilt angle), in order to reach the optimum values for output characteristic or responses (total energy, crack initiation energy and crack propagation energy). Taguchi approach was used here to design the experiment according to three parameters (rotational speed welding, traversing speed, and tilt angle), each of them with four levels. The L16 orthogonal array and signal to noise ratio analysis was used to find the optimum parameters set. Finally, the significance of influence between each of these parameters is determined by the ANOVA analysis.

\subsection{Friction Stir Welding (FSW)}

Friction stir welding (FSW) is a relatively new solidstate joining process. It was invented and patented by The Welding Institute (UK) [1], providing high quality of a product, as well as short production time and low energy input [2]. The process of friction stir welding is rising the temperature by rotating a special tool at the contact line of the work pieces until the plastic state is reached. Fig. 1 shows the FSW operation. In simple words, a nonconsumable rotating tool with designed pin (probe) and shoulder is inserted into the edges of the plates to join. The pin traverses along the line of joint with the determined speed $(\mathrm{m} / \mathrm{s})$ and the shoulder glides over the plates [3].

The friction stir welding operation has several phases. It starts with facing the work pieces and clamping them; then the pin plunges and penetrates into the plates until the tool shoulder has penetrated into the material at prescribed depth (a few tenths of a millimeter) enabling sufficient pressure and producing enough heat by friction and plastic deformation for establishing the appropriate welding conditions $[4,5]$. Then, the fast rotating tool starts moving along the facing contact of the plates (joint line), generating heat by friction between the head probe and the plate. Majority of heat generated (about 95\%) in the welding operation is transferred to the work piece and the remaining (about 5\%) flows back into the tool. The material around the pin becomes soft and moves it from the front of the pin to the back by the rotation of the pin $[4,5]$.

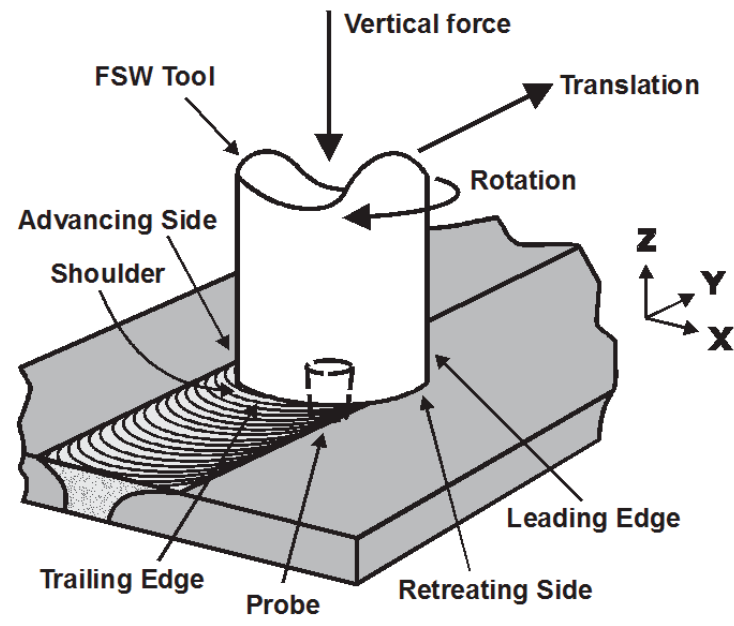

Figure 1 Schematic representation of FSW [6]

The process takes place in the solid phase, below the melting point of the materials to be joined and this gives the possibility of producing high quality joints, $[7,8]$. This advantage enables joining of materials that are otherwise difficult to weld, typically some types of aluminummagnesium and copper alloys. Friction stir welding can use purpose-designed equipment or modified existing machine tool technology. The process is also suitable for automation and is adaptable for robot use, [7]. There are many other advantages, such as low distortion and shrinkage, even in long welds; desired mechanical properties such as strength; no hot cracks, no gas props; energy efficiency; possibility to weld large thickness of aluminum and copper; no welding fumes and no UV radiation; some tolerances to imperfect weld preparations - thin oxide layers can be accepted; no grinding, brushing or pickling required in mass production $[7,9]$.

The most important parameters which affect the friction stir welding product are, [10]

- Tool rotation speed

- Traverse speed

- Tool geometry 
- Tilt angle

- Axial load

- $\quad$ Plunge depth

- Backing plate.

While the quality of a weld joint product is depending on these parameters during the welding process, the tool rotation speed $(\omega, \mathrm{rpm})$, traverse speed $(v, \mathrm{~mm} / \mathrm{min})$ and tool geometry are the main important sources of heat generation during the welding operation. Therefore, the values of these input parameters have an essential effect in deciding the quality of welded joints. Various industries of welding follow the conventional experimental procedure, i.e., varying one parameter at a time while keeping the other parameters constant. This conventional parametric design of the experiment consumes a lot of time and costs $[3,11]$. Taguchi method introduced tools for design the experiment with reduced number of experiment runs and no additional cost.

\subsection{Taguchi Method}

Taguchi method, also known as robust design method pioneered by Dr. Taguchi, greatly improves engineering productivity. It is a powerful statistical technique for improving product/process design and solving production problems. It is based on the idea that quality should be measured by the deviation from a specified target value, rather than by conformance to preset tolerance limits. Quality cannot be ensured through inspection and rework, but must be built in through the appropriate design of the process and product. In particular, there are three concepts as the main contributions in Taguchi method - orthogonal arrays; robustness; and quality loss function, [12].

The number of experimental runs depends on the number of parameters or factors and their levels. It increases as the number of parameters and their levels are increasing. In traditional factorial method, the number of required experiments is calculated by factorial of numbers of parameters or factors and number of their levels. In the 1980s, Taguchi presented new design, called Taguchi orthogonal array, as optimization design that can be used to obtain the necessary information by an experiment frequency that is less than the factorial experiment without loss of the main data. For example, to design an experiment for three parameters with four levels for each of them, one needs $4^{3}=64$ runs by using full factorial and, by using Taguchi orthogonal array, one needs only 16 runs. The number of required experiments will become huge if we have a big number of parameters and levels. In the case of eight parameters and four levels for each of them, by Taguchi orthogonal one needs 32 experiment runs, whereas, by factorial design, $4^{8}=65536$ experiment runs should be done [13].

Taguchi approach to improving quality of product and process emphasizes the moving of quality into the design stage. It is based on belief that minimizing the variation leads to quality improvement. The system input variables are divided into control factors and noise (uncontrollable) factors. The factors that cannot be controlled are the environmental factors or other factors that cannot be regulated due to being impractical or very expensive [12]. To eliminate or decrease the effect of these noise factors,
Taguchi introduced the signal to noise ratio, $\mathrm{S} / \mathrm{N}$, between the average response value caused by control factors and variability as consequence of noise factors [12]. Depending on the nominal specification, $\mathrm{S} / \mathrm{N}$ ratio is defined as:

- $\quad$ Nominal-the-Better (NB), when the specified value is the most desired in neither a smaller nor a larger value (for example, ratios of chemical species, or parts in mechanical fitting that have nominal dimensions). The model of (NB) is

$\mu=10 \log _{10}\left(\frac{y^{2}}{s^{2}}-\frac{1}{n}\right)$

- $\quad$ The Higher-the-Better (HB) or the Larger the Better (LTB), when the response is desirable (for example yield strength of the material, critical current, mass flow rates for filling fluid, etc.) The model of (HB) is,

$$
\mu=10 \log _{10}\left(\frac{1}{n} \sum_{i=1}^{n} \frac{1}{y_{i}^{2}}\right)
$$

- The Lower-the-Better (LB) or the Smaller the Better (STB), when the characteristic is not wanted, (for example, rate of engine fuel consumption, weight of airplane parts, etc.). The model of LB is,

$$
\mu=10 \log _{10}\left(\frac{1}{n} \sum y_{i}^{2}\right)
$$

where $\mu$ is $\mathrm{S} / \mathrm{N}$ Ratio, $y$ is measurable statistic of response, $\mathrm{s}^{2}$ is the sample variance of $n$ unit [12].

Finally, let us mention that Variance ANOVA is a statistical tool used to help decision-making by detecting any differences in the average performance of collections of items which are tested [14]. In the Taguchi approach, statistical ANOVA is used to investigate which of input parameters significantly affect the quality of the response or output characteristics.

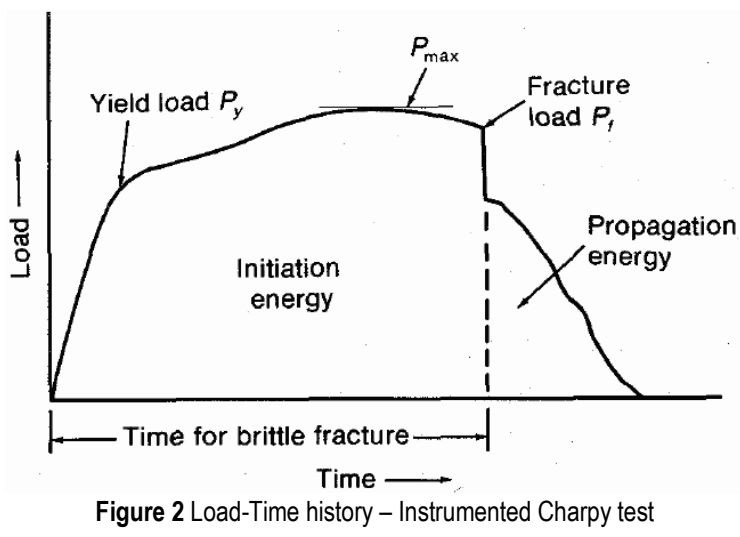

\subsection{Instrumented Charpy Pendulum}

The Charpy test measures only total energy absorbed in fracturing a specimen, unless it is instrumented to record the load-time history, [15, 16], enabling separation of energy for initiating and propagating of fracture (crack), Fig. 2. In this way, one can get better insight of material 
behavior under impact loading, because its resistance to crack initiation and propagation is separated.

\section{EXPERIMENT}

In this study, friction stir welding process with three parameters (welding speed, rotation speed, and tilt angle of the tool), each with four levels, is presented. As shown in Tab.1, these parameters were used to weld aluminum alloy 5083 (AA 5083) plates, with thickness of $5.5 \mathrm{~mm}$, length of $1000 \mathrm{~mm}$ and width of $500 \mathrm{~mm}$. The thickness was reduced to $5.5 \mathrm{~mm}$ by hot rolling in several steps from the original plate thickness of $7.2 \mathrm{~mm}$. Then, the plates were cut into a set of strips with a length of 260 $\mathrm{mm}$, width of $45 \mathrm{~mm}$ and a $5.5 \mathrm{~mm}$ thickness, Fig. 3. Taguchi approach was used for designing of experiments and analysis of the results.

Table 1 Parameters and their level values.

Table 1 Parameters and their level values.
\begin{tabular}{|c|c|c|c|c|}
\hline \multirow{2}{*}{ Parameters } & \multicolumn{4}{|c|}{ Levels } \\
\cline { 2 - 5 } & 1 & 2 & 3 & 4 \\
\hline Welding speed $(\mathrm{mm} / \mathrm{min}) S$ & 500 & 600 & 700 & 800 \\
\hline Rotation speed (rpm) $R$ & 75 & 100 & 125 & 150 \\
\hline Tilt angle $\left(^{\circ}\right)$ & 1 & 2 & 3 & 4 \\
\hline
\end{tabular}

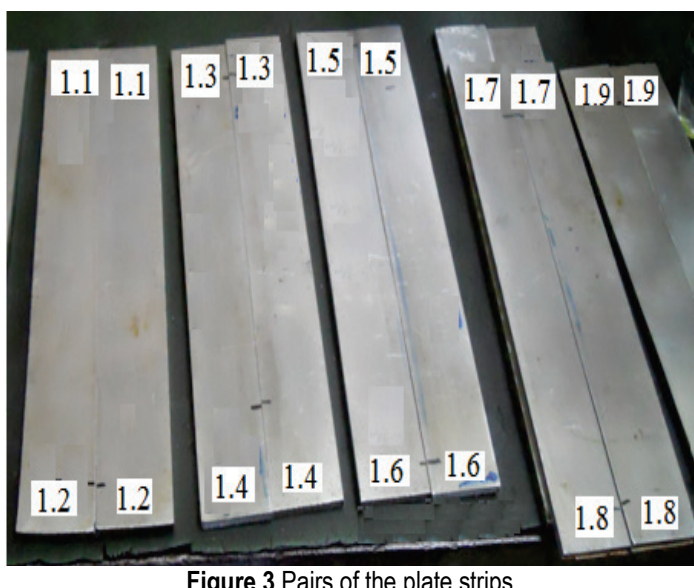

The chemical composition of AA 5083 and its mechanical properties are shown in Tables 2 and 3, respectively.

Table 2 Chemical Composition of the Investigated AA 5083

\begin{tabular}{|c|c|c|c|c|}
\hline $\mathrm{Mg}$ & $\mathrm{Mn}$ & $\mathrm{Cu}$ & $\mathrm{Fe}$ & $\mathrm{Si}$ \\
\hline 5.13 & 0.72 & 0.01 & 0.34 & 0.11 \\
\hline $\mathrm{Ti}$ & $\mathrm{Zr}$ & $\mathrm{Zn}$ & $\mathrm{Cr}$ & $\mathrm{Na}$ \\
\hline 0.02 & 0.02 & 0.51 & 0.008 & 0.0005 \\
\hline
\end{tabular}

Table 3 Mechanical Properties of AA5083

\begin{tabular}{|c|c|c|c|c|}
\hline $\begin{array}{c}\text { Deformation } \\
(\%)\end{array}$ & $\begin{array}{c}\text { Thickness of } \\
\text { specimens } \\
(\mathrm{mm})\end{array}$ & $\begin{array}{c}\text { Yield } \\
\text { strength } \\
(\mathrm{MPa})\end{array}$ & $\begin{array}{c}\text { Ultimate } \\
\text { strength } \\
(\mathrm{MPa})\end{array}$ & $\begin{array}{c}\text { Elongation } \\
\text { max (\%) }\end{array}$ \\
\hline 16.6 & 5.5 & 300.50 & 369.1 & 9.8 \\
\hline
\end{tabular}

In this study, three parameters that have strong effect on the microstructure, mechanical properties, and residual stress profile of friction stir welding process were used. It is because these parameters are the main sources of the heat generated during the operation $[4,5,10]$. For each of these parameters, 4 levels were used in this study.

Welding parameters (tool rotation speed, welding traverse speed, and tilt tool angle) were determined and each of them had four levels. Depending on Taguchi method, orthogonal arrays were selected according to these numbers of parameters and their levels. The number of degrees of freedom was calculated as: $(4-1)+(4-1)$ $+(4-1)+6=15$ which means that the minimum experiment runs was 16 . In this case, it was found that the suitable orthogonal array was L16 that means the experiment had to be performed 16 times. Tab. 4 represents the orthogonal array L16 with the distribution of the parameters and their level values.

Table 4 Orthogonal array L16 with values of the parameters

\begin{tabular}{|c|c|c|c|}
\hline $\begin{array}{c}\text { Experiment } \\
\text { number }\end{array}$ & $\begin{array}{c}\text { Rotation } \\
\text { rotational speed } \\
(\mathrm{rpm})\end{array}$ & $\begin{array}{c}\text { Welding } \\
\text { horizontal speed } \\
(\mathrm{mm} / \mathrm{min})\end{array}$ & $\begin{array}{c}\text { Tilted } \\
\text { angle }\left(^{\circ}\right)\end{array}$ \\
\hline 1 & 500 & 75 & 1 \\
\hline 2 & 500 & 100 & 2 \\
\hline 3 & 500 & 125 & 3 \\
\hline 4 & 500 & 150 & 4 \\
\hline 5 & 600 & 75 & 2 \\
\hline 6 & 600 & 100 & 1 \\
\hline 7 & 600 & 125 & 4 \\
\hline 8 & 600 & 150 & 3 \\
\hline 9 & 700 & 75 & 3 \\
\hline 10 & 700 & 100 & 4 \\
\hline 11 & 700 & 125 & 1 \\
\hline 12 & 700 & 150 & 2 \\
\hline 13 & 800 & 75 & 4 \\
\hline 14 & 800 & 100 & 3 \\
\hline 15 & 800 & 125 & 2 \\
\hline 16 & 800 & 150 & 1 \\
\hline
\end{tabular}

\section{RESULTS AND DISCUSSION}

After the design of the experiments and preparing of the plate strips, the 16 experiments were run according to the Table 5 input data, to obtain absorbed energy, as well as energies for crack initiation and propagation, using the average value from 2 specimens in diagrams Load-Time, as illustrated in Fig. 4 for the experiment No. 2.

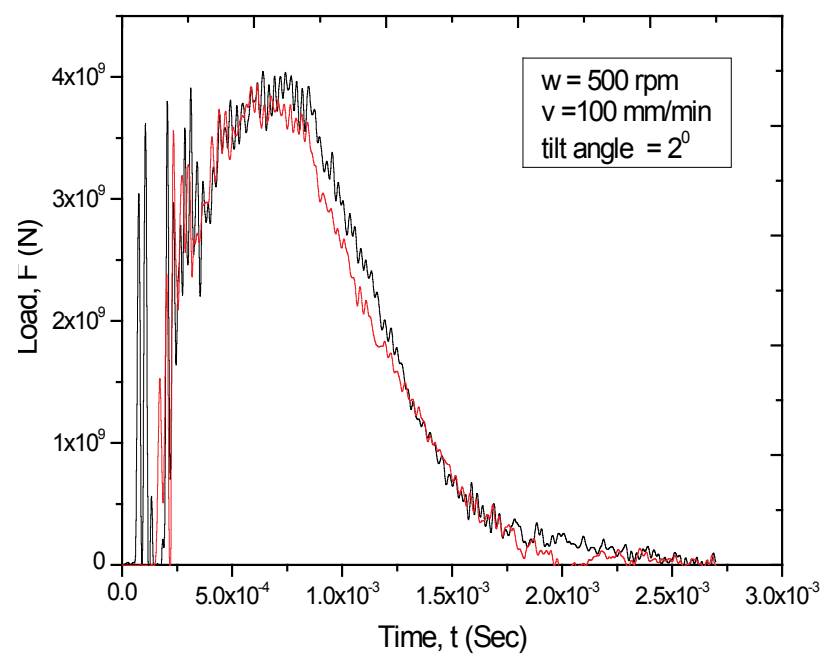

Figure 4 Typical Load-Time diagrams (experiment No. 2)

Results of measured values of absorbed energy, as well as energies for crack initiation and propagation, are given in Tab. 5 for each of 16 runs.

In this study, the influence of rotational tool speed, transverse welding speed and tool tilt angle parameters in total, initiation propagation energy was required, as well as responses of the signal to noise ratio $(\mathrm{S} / \mathrm{N})$ and means for each parameter. The desired values for each response are 
their maximum, since Eq. (2) (the Higher-the-Better (HB) or the Larger the Better (LTB)) were used in this calculation. By using Minitab software, based on Tab. 5 data, the experimental results were transformed into the means and signal to noise ratios $(\mathrm{S} / \mathrm{N})$. The mean response of raw data and signal-to-noise ratio of absorbed energy was calculated and is shown in Tabs. 6-7.

Table 5 Results of the three parameters in the 16 experiment runs

\begin{tabular}{|c|c|c|c|}
\hline $\begin{array}{c}\text { Experiment } \\
\text { number }\end{array}$ & $\begin{array}{c}\text { Absorbed } \\
\text { Energy }(\mathrm{J})\end{array}$ & $\begin{array}{c}\text { Crack initiation } \\
\text { energy }(\mathrm{E} i)\end{array}$ & $\begin{array}{c}\text { Crack propagation } \\
\text { energy }(\mathrm{Ep})\end{array}$ \\
\hline 1 & 15.50 & 7.00 & 8.00 \\
\hline 2 & 19.25 & 9.30 & 10.00 \\
\hline 3 & 22.90 & 11.00 & 12.00 \\
\hline 4 & 16.20 & 11.00 & 4.80 \\
\hline 5 & 18.50 & 6.8 & 12.00 \\
\hline 6 & 18.30 & 12.00 & 6.80 \\
\hline 7 & 20.20 & 11.00 & 9.10 \\
\hline 8 & 20.30 & 11.00 & 9.60 \\
\hline 9 & 14.90 & 8.30 & 6.60 \\
\hline 10 & 16.10 & 7.60 & 8.50 \\
\hline 11 & 18.70 & 10.00 & 8.40 \\
\hline 12 & 20.80 & 10.00 & 11.00 \\
\hline 13 & 18.50 & 10.00 & 8.40 \\
\hline 14 & 19.80 & 11.00 & 9.10 \\
\hline 15 & 17.50 & 9.30 & 8.20 \\
\hline 16 & 15.40 & 6.30 & 9.20 \\
\hline
\end{tabular}

Table 6 Response table for signal to noise ratios larger is better

\begin{tabular}{|c|c|c|c|}
\hline Level & $\begin{array}{c}\text { Rotational } \\
\text { speed }(\mathrm{rpm})\end{array}$ & $\begin{array}{c}\text { Traverse speed } \\
(\mathrm{mm} / \mathrm{min})\end{array}$ & $\begin{array}{c}\text { Tilt angle } \\
\left({ }^{\circ}\right)\end{array}$ \\
\hline 1 & 25.16 & 24.43 & 24.50 \\
\hline 2 & 25.71 & 25.25 & 25.56 \\
\hline 3 & 24.85 & 25.90 & 25.69 \\
\hline 4 & 24.97 & 25.11 & 24.94 \\
\hline Delta & 0.86 & 1.48 & 1.19 \\
\hline Rank & 3 & 1 & 2 \\
\hline
\end{tabular}

Table 7 Response table for means

\begin{tabular}{|c|c|c|c|}
\hline Level & $\begin{array}{c}\text { Rotational } \\
\text { speed }(\mathrm{rpm})\end{array}$ & $\begin{array}{c}\text { Traverse speed } \\
(\mathrm{mm} / \mathrm{min})\end{array}$ & $\begin{array}{c}\text { Tilt angle } \\
\left({ }^{\circ}\right)\end{array}$ \\
\hline 1 & 18.35 & 16.74 & 16.86 \\
\hline 2 & 19.32 & 18.36 & 19.01 \\
\hline 3 & 17.63 & 19.82 & 19.48 \\
\hline 4 & 17.80 & 18.18 & 17.75 \\
\hline Delta & 1.70 & 3.09 & 2.61 \\
\hline Rank & 3 & 1 & 2 \\
\hline
\end{tabular}

The output results of the main effect and signal to noise ratio $(\mathrm{S} / \mathrm{N})$ are plotted in Figs. 5 and 6, respectively.
It is clear that the absolute energy reaches the highest value at the second level of rotational speed, the third level of welding speed, and the third level of tilt angle. So, the set of parameters which gets the maximum value of absolute energy is: rotational speed of $600 \mathrm{rpm}$, traverse or welding speed of $125 \mathrm{~mm} / \mathrm{min}$, and tilt angle $3^{\circ}$.

By the same procedure, it was found that the optimum parameter levels set for the energy for crack initiation are $600 \mathrm{rpm}, 125 \mathrm{~mm} / \mathrm{min}$, and $3^{\circ}$. For crack propagation energy, only different level was the tilt angle and the maximum was found to be at $\alpha=2^{\circ}$.

When the optimum set of parameter levels was determined, the optimum performance of the response under the optimum condition was predicted. The optimum value of the response characteristic was estimated as follows $[10,17]$ :

$\Upsilon=\frac{R}{N}+\left(\varepsilon_{\mathrm{f} l \mathrm{av}}-\frac{R}{N}\right)+\left(\varepsilon_{\mathrm{f} f \mathrm{av}}-\frac{R}{N}\right)+\left(\varepsilon_{\mathrm{b} \mathrm{f} \mathrm{av}}-\frac{R}{N}\right)-\frac{R}{N}(5)$

where $Y$ is the optimum value of response characteristic (herein the absolute energy), $R / N$ the overall mean of absolute energy values in 16 experiments, $\varepsilon$ the absolute energy, $\varepsilon_{\mathrm{fl}}$ av the average absolute energy at the second level of rotational speed $(600 \mathrm{rpm}), \varepsilon_{\mathrm{f} f 2 a v}$ the average absolute energy at the third level of welding speed $(125 \mathrm{~mm} / \mathrm{min})$, $\varepsilon_{\mathrm{ff}}$ av the average absolute energy at the third level of tool tilt angle $\left(3^{\circ}\right)$. By substituting data from Tabs. 6 and 7 in Eq. 5, optimum value of response characteristic (namely absolute crack energy) was found as:

$$
\Upsilon=18.275+(19.325-18.275)+(19.825-18.275)+
$$$$
(19.475-18.275)=22.075
$$

The optimum design was determined to be: rotational speed - L2, welding speed - L3 and tilt angle - L3. It should be noted that the above combination of factor levels is among the sixteen combinations tested in the experiment and the average absolute energy was found to be 20.8. By comparing these two response values (L2 and L3), it was found that the two values are close together and there is only about $6.12 \%$ deviation between them (predicted - 22.075 and actual - 20.80).
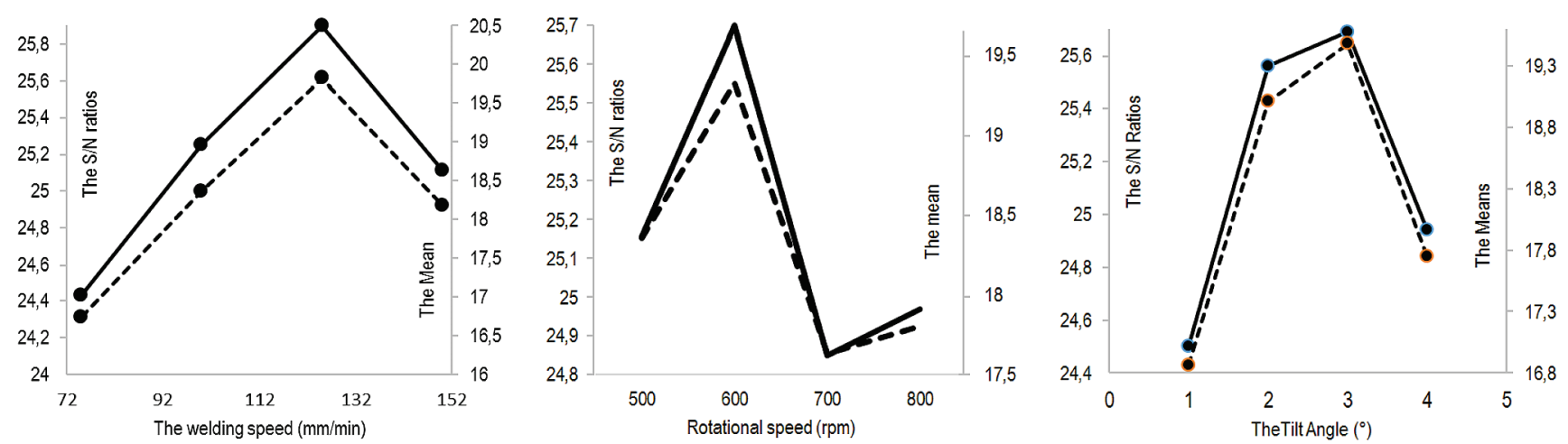

Figure 5 Plotted mean and $\mathrm{S} / \mathrm{N}$ ratio effect on the welding speed, rotational speed, and tilt angle

\section{ANALYSIS OF VARIANCE (ANOVA)}

The target from Analysis of variance (ANOVA) test is identifying the process parameters that are statistically significant [10]. In this study, the purpose of the ANOVA test was to investigate the significance of the rotational speed, welding speed and tilt tool angle which affect the absolute energy of friction stir welding operation. Tab. 8 
displays the ANOVA results - the contribution of the three parameters (rotational speed, welding speed, and tilt tool angle) on the absolute crack energy of fracture toughness. A factor of a higher percentage contribution means that it has a great influence on the performance at little variation and vice-versa. From the results obtained by ANOVA, the parameter that mostly affects the absolute energy in friction stir welding operation is the welding speed with $44.3 \%$. The second is the tilt tool angle with $39.4 \%$ and the last, by $16.3 \%$ rotational speed. The pie chart in Fig. 6 shows the percentage contribution for each parameter.

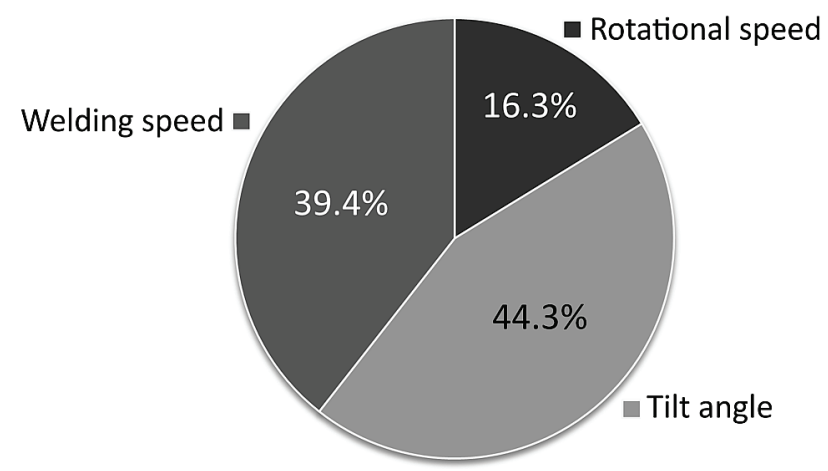

Figure 6 Contribution of 3 parameters to toughness

Table 8 Analysis of Variance (ANOVA) for absolute crack energy (E), Using Adjusted SS for Tests

\begin{tabular}{|c|c|c|c|c|c|c|c|c|}
\hline Source & $D F$ & Seq SS & Adj $S S$ & $\operatorname{Adj} M S$ & $F$ & $P$ & $\begin{array}{c}\% \% \\
\text { contribution }\end{array}$ & $\begin{array}{l}\text { \% Parameters } \\
\text { contribution }\end{array}$ \\
\hline Rotational speed (rpm) & 3 & 7.025 & 7.025 & 2.342 & 0.39 & 0.762 & 8.91 & 16.3 \\
\hline Welding speed (Traverse speed) $(\mathrm{mm} / \mathrm{min})$ & 3 & 19.136 & 19.136 & 6.397 & 1.07 & 0.428 & 24.27 & 39.4 \\
\hline Tilt angle $\left({ }^{\circ}\right)$ & 3 & 17.019 & 17.019 & 5.673 & 0.95 & 0.472 & 21.59 & 44.3 \\
\hline Error & 6 & 35.645 & 35.645 & 5.941 & & & 45.22 & \\
\hline Total & 15 & 78.825 & & & & & 100 & 100 \\
\hline
\end{tabular}

$D F$ - Degrees of freedom, Seq $S S$ - Sequential sum of squares, Adj $S S$ - Adjusted sum of square, Adj MS - Adjusted mean square, $F$ - Fisher ratio, $P$ probability that exceeds the $95 \%$ confidence level.

\section{CONCLUSIONS}

Based on the results presented in this paper, the following conclusions were made:

- The contribution of three welding parameters (rotational speed, welding speed, and tilt tool angle) to the fracture toughness energy in friction stir welding operation was successfully determined by Taguchi method.

- The welding speed had the highest effect, followed by tilt angle, whereas rotational speed had the lowest effect.

- The optimum set of these parameters for the total energy and the energy for crack initiation was determined (rotational speed at $600 \mathrm{rpm}$, welding speed at $125 \mathrm{~mm} / \mathrm{min}$ and tilt angle $3^{\circ}$ ), whereas, for the energy for crack propagation only the tilt angle was different ,i.e. its value was $2^{\circ}$.

\section{REFERENCES}

[1] Nourani, M., Milani, A. S., \& Yannacopoulos, S. (2011). Taguchi optimization of process parameters in friction stir welding of 6061 aluminum alloy: A review and case study. Engineering, 3(02), 144. https://doi.org/10.4236/eng.2011.32017

[2] Pachal, A. S., Bagesar, A. (2013). Taguchi optimization of process parameters in friction welding of 6061 aluminum alloy and 304 steel: a review. International Journal of Emerging Technology and Advanced Engineering (IJETAE), 3(4), 229-233.

[3] Pawar, S. P. \& Shete, M. T. (2013). Optimization of friction stir welding process parameter using Taguchi method and response surface methodology: A Review. International Journal of Research in Engineering and Technology (IJRET), 2(12), 551-554. https://doi.org/10.15623/ijret.2013.0212092

[4] Eramah, A., Rakin, M., Veljić, D., Radović, N., Zrilic, M., \& Perović, M. (2013). Influence of Friction Stir Welding Parameters on Properties of 2024 T3 Aluminium Alloy Joints. Thermal Science, 17, 21-27.
[5] Mohan, R., Rajesh, N. R., \& Kumar, S. (2014). Finite element modeling for maximum temperature in friction stir welding of AA1 100 and optimization of process parameter by taguchi method. International Journal of Engineering Research \& Technology (IJERT), 3(5), 728-733. https://doi.org/10.15623/ijret.2014.0305135

[6] He, X., Gu, F., Ball, A. (2014). A review of numerical analysis of friction stir welding. Progress in Materials Science, 65, 1-66. https://doi.org/10.1016/j.pmatsci.2014.03.003

[7] http://www.twi-global.com/capabilities/joining-technologies/friction-processes/friction-stir-welding/benefits-and-advantages/ (Accessed: September, 2017)

[8] Kaushik, V. \& Singh, H. (2014). Optimization of Mechanical Properties in Friction Stir Welding by using Taguchi Method. International Journal of Engineering Research \& Technology (IJERT), 3(11), 590-594.

[9] http://www.bil-ibs.be/sites/default/files/FSWAcier/fsw.pdf (Accessed: September, 2017)

[10] Karur, A. S., Chipli, S., \& Singh, A. (2015). Optimization of FSW Parameters to Improve the Mechanical Properties of AA2024-T351 Similar Joints Using Taguchi Method. Journal of Mechanical Engineering and Automation, 5(3B), 27-32.

[11] Lakshminarayanan, A. K. \& Balasubramanian, V. (2008). Process parameters optimization for friction stir welding of RDE-40 aluminium alloy using Taguchi technique. Transactions of Nonferrous Metals Society of China, 18(3), 548554. https://doi.org/10.1016/S1003-6326(08)60096-5

[12] Šibalija, T. V. \& Majstorović, V. D. (2015). Advanced Multiresponse Process Optimisation: An Intelligent and Integrated Approach. Springer.

[13] Ardak, M. B. \& Phate, M. M. (2014). Formulation of a Model and Analysis of Mechanical Timer Parameters by Using Response Surface Method in MINITAB. International Journal for Research in Applied Science and Engineering Technology (IJRASET), 2(6), 269-276.

[14] Kowalczyk, M. (2014). Application of Taguchi and ANOVA methods in selection of process parameters for surface roughness in precision turning of titanium. Advances in Manufacturing Science and Technology, 38(2). https://doi.org/10.2478/amst-2014-0008

[15] Čamagić, I., Jović, S., Radojković, M., Sedmak, S. A., Sedmak, A., Burzić, Z., \& Delamarian, C. (2016). Influence 
of Temperature and Exploitation Period on the Behaviour of a Welded Joint Subjected to Impact Loading. Structural Integrity and Life, 16(3), 179-185.

[16] Eramah, A. M. M., Tadić, S., \& Sedmak, A. (2013). Impact Fracture Response of Friction Stir Welded Al-Mg Alloy. Structural Integrity and Life, 13(3), 171-177.

[17] Salehi, M., Saadatmand, M., \& Mohandesi, J. A. (2012). Optimization of process parameters for producing AA6061/SiC nanocomposites by friction stir processing. Transactions of Nonferrous Metals Society of China, 22(5), 1055-1063. https://doi.org/10.1016/S1003-6326(11)61283-1

\section{Contact information:}

Abuajila RAWENI, PhD student

University of Belgrade

Faculty of Mechanical Engineering

Kraljice Marije 16

11020 Belgrade 35, Serbia

Vidosav MAJSTOROVIĆ, PhD, Professor

University of Belgrade

Faculty of Mechanical Engineering

Kraljice Marije 16

11020 Belgrade 35, Serbia

\section{Aleksandar SEDMAK, PhD, Professor}

University of Belgrade

Faculty of Mechanical Engineering

Kraljice Marije 16

11020 Belgrade 35 , Serbia

asedmak@mas.bg.ac.rs

Srdjan TADIĆ, PhD

Innovation Center of the Faculty of Mechanical Engineering

Kraljice Marije 16

11020 Belgrade 35, Serbia

Snežana KIRIN, PhD

Innovation Center of the Faculty of Mechanical Engineering

Kraljice Marije 16

11020 Belgrade 35, Serbia 